\title{
Preparation and Characterisation of Sustained Released Dosage Form for Ketoprofen using Natural Gums
}

\author{
Srinivasa Rao Baratam*, Made Vijay Harsha \\ St Ann's College of Pharmacy, Pharmaceutical Technology, Cantonment, Vizianagaram, Andhra Pradesh, INDIA.
}

\begin{abstract}
Objective: The major objective of this work is to formulate a sustained launch matrix drugs the use of cashew and neem gum. Ketoprofen turned into decided on as a version drug because of the low half-life. Hence sustained dosage forms are formulated to lessen the dosage frequency. Methods: Ketoprofen matrix tablets were formulated by employing cashew gum and neem gum as a release rate retardant material and used in $10 \%, 20 \%, 30 \%$ and $40 \%$ Concentration levels. Wet granulation method was used to develop sustained release tablets. Tablet was evaluated in terms of flow properties of blended powders and the average weight, drug content hardness, in vitro dissolution studies and fourier transformationinfrared spectroscopyn (FT-IR) were determined. Drug release was evaluated with zero and the first order for release kinetics, Higuchi, Korsmeyer peppas models for the release mechanism. Results: The hardness of the tablets ranged from 5.5 to $6.8 \mathrm{Kg} / \mathrm{cm}^{2}$ and the friability values were less than $1 \%$ indicating that the matrix tablets were compact and hard. All the formulations satisfied the content of the drug as they contained 99.1 to
\end{abstract}

$100.8 \%$ of ketoprofen, KCS8 released 99.2 of drug in $12 \mathrm{hrs}$ and considered as optimized formulas. KCS8 formulation has shown drug release by zero order kinetics. This data reveals that drug release follows fickian diffusion mechanism Peppas model. Conclusion: The present study could establish the suitability of neem gum, cashew gum as Controlled released (CR) polymer in the design of matrix tablets.

Key words: Ketoprofen, Cashew Gum, Neem Gum, Controlled Release and Wet Granulation.

\section{Correspondence}

Mr. Srinivasa Rao Baratam

Assistant Professor, Department of Pharmaceutical Technology, St. Ann's College of Pharmacy, Andhra University, Vizianagaram- 535003, Andhra Pradesh, INDIA.

Phone no: +91-9441389610

Email: srinivas.baratam077@gmail.com

DOI: 10.5530/ijpi.2020.1.10

\section{INTRODUCTION}

Although natural gums and their derivatives are used widely in pharmaceutical dosage forms, their use as biodegradable polymeric materials to deliver bioactive agents has been hampered by the synthetic materials. In this review, recent developments in the area of natural gums and their derivatives as carriers in the sustained release of drugs are explored. ${ }^{1}$ In recent years, polymers those are derived from plant origin have evoked tremendous interest because of their diverse pharmaceutical applications such as diluent, binder, disintegrant in tablets, thickeners in oral liquids, protective colloids in suspensions, gelling agents in gels and bases in suppository. ${ }^{2}$ They are also used in cosmetics, paints, textiles and papermaking. ${ }^{3}$ Also the natural excipients are preferred on the synthetic and semi synthetic ones because of their lack of toxicity, low cost, soothing action, availability and nonirritant nature of the excipients. ${ }^{4,5}$ Cashew gum is the exudate from the stem bark of Anacardium occidentale (family: Anacardiaceae). ${ }^{6}$ Neem gum is obtained from the trees of Azadirachta indica (family: Meliaceae). ${ }^{7}$ Studies were performed on neem gum and cashew gum for its sustained release property. ${ }^{8,9}$ The oral route is widely known, effective, important, self-remedy and value-effective. Tablet adopted its reputation and availability inside the marketplace because of its ease of producing, management comfort, dosing accurateness and higher stability than other dosage forms. ${ }^{10}$ Sustained release matrix tablets have given a new evolution towards novel drug delivery of pharmaceutical technology. ${ }^{11}$ Ketoprofen is a non-steroidal anti-inflammatory drug (NSAID) used for anti-inflammatory, analgesic and antipyretic. ${ }^{12}$ Ketoprofen is a model drug in formulating sustained release dosage forms due to its low plasma elimination half-life and less solubility in water and Ketoprofen is classified as Class II drugs according to BCS (Biopharmaceutical Classi- fication system) indicating low solubility and high permeability ( $85 \%$ or more active pharmaceutical ingredient is absorbed) with oral bioavailability is $90 \% .^{13}$ The aim of the current study was to design sustained release oral matrix tablets of ketoprofen using wet granulation method with varying blends of natural gums. The objective was to enhance the drug release modifying properties of the polymers leading to the formation of optimized formulation of the model drug with different concentrations.

\section{MATERIALS AND METHODS}

\section{Materials}

Cashew gum was obtained from cashew plantation as natural exudates from the stem barks of the plant Anarcadium occidentale Linn (family, Anacardiaceae) at Vizianagaram. Neem gum obtained from the Neoteric DCBA ideas, Tamil Nadu, India. Ketoprofen was obtained from Yarrow Chem Limited, Mumbai. Micro Crystalline Cellulose was obtained from SD fine chem limited, Mumbai. PVP K- 30 was obtained from Loba Chemi, Mumbai. All other reagents and chemicals were of analytical grade.

\section{Extraction of cashew gum and neem gum}

The gum was cleaned by removing the bark and other extraneous materials by hand and dried in a hot air oven at $50^{\circ} \mathrm{C}$ for about $8 \mathrm{hrs}$ until it became sufficiently brittle. The dried gum was manually sorted into light colored and dark colored grades. The light colored grade was selected for further processing by milling in a domestic blender into a fine powder and designated as crude cashew gum (CCG). $100 \mathrm{~g}$ of CCG was 
dissolved in $200 \mathrm{ml}$ of distilled water and allowed to stand for $24 \mathrm{hrs}$ with intermittent stirring. The gum mucilage was strained with calico to remove any insoluble debris or impurities and precipitated with 350 $\mathrm{ml}$ of $96 \%$ ethanol. The precipitated gum was re-filtered and washed with diethyl ether and dried in a hot air oven at $50^{\circ} \mathrm{C}$ for $8 \mathrm{hrs}$. The dried purified gum was milled and screened through 85 sieve. The powdered gum was used in subsequent tests and analyses as Purified Cashew Gum (PCG). ${ }^{13}$ Crude Neem Gum (CNG) was collected from the incised bark of $A$. indica trees from Neoteric DCBA Ideas. The collected neem gum was hydrated insufficient amount of distilled water for 5 days with intermittent stirring and extraneous materials were removed by filtering using a Buchner funnel under negative pressure. The gum from the filtered slurry was precipitated with $99.8 \%$ ethanol; the precipitated gum was filtered, washed several times with acetone and dried in a hot air oven at $30^{\circ} \mathrm{C}$ for $96 \mathrm{~h}$ before milling and sieving with a mesh 60 and then stored in an amber-colored bottle until needed. ${ }^{14}$ Samples of crude gum, neem gum and extracted powder were shown in Figure 1.

\section{Fourier transform infrared spectroscopy (FT-IR) Studies}

FTIR studies were performed on drug, placebo and the optimized formulation. Fourier transform infrared spectrophotometry study was done with Bruker Alpha II with wave no. range 4000 to $400 \mathrm{~cm}^{-1}{ }^{12}$

\section{Preparation of sustained release of ketoprofen}

Sustained release tablet was prepared by wet granulation method according to the formula given in the table. Various concentrations levels of $10 \%, 20 \%, 30 \%$ and $40 \%$ natural polymers were used. Polyvinyl pyrrolidine $\mathrm{K} 30$ was used as a binding agent at $1 \%$ concentration level. Total of eight formulations was developed using a constant $200 \mathrm{mg}$ of ketoprofen with varying amount of excipients. The polymers being used in formulations are neem gum, cashew gum. The drug and polymer was mixed by a small portion of both each time and blend it to get a uniform mixture and kept aside. Then all the ingredients weighed and kept aside. Then all the ingredients weighed are mixed in geometrical order excluding magnesium stearate and talc to get a uniform blend. All ingredients were mixed for 20 mins and triturated well using mortar. Isopropyl alcohol solvent was added dropwise until to get granular mass. Then the compact mass was passed to the 8 -mesh sieve and dried at $70^{\circ} \mathrm{C}$ using hot air oven. After the drying, the dried product was passed through 16 mesh sieve separately. The drug and polymer was mixed by a small portion of both each time and blend it to get a uniform mixture and kept aside. Then all the ingredients weighed and kept aside. Then all the ingredients weighed are mixed in geometrical order excluding magnesium stearate and talc to get a uniform blend. Finally, the mixture is blended with magnesium stearate and tablets were compressed of $8 \mathrm{~mm}$ sized concave round punch to get tablet using Shakti 8 station tablet compression machine. Compositions of all batches are represented in Table 1 .

\section{Micromeritic evaluation}

The flow characteristics of powder (i.e., a mix of powders before compression) were assessed by measure the angle of repose by stationary funnel technique and Carr's compressibility index by normal standard tapping technique Hausner ratios were determined. ${ }^{15}$

Hausner ratio $=\mathrm{Dt} / \mathrm{Db}$,

Compressibility Index $(\%)=[(\mathrm{Dt}-\mathrm{Db}) \times 100] / \mathrm{Dt}$,

where, $\mathrm{Dt}$ is the tapped density, $\mathrm{Db}$ is the bulk density.

The tablets were characterized for weight variation and hardness employing a Monsanto hardness tester and friability employing a Roche friabilator equipment.

\section{Drug content}

At random 10 tablets were chosen from completely different batches of formulations. The tablets were then pulverized, mixed by mortar. An accurately weighed amount of pulverized tablets was extracted with methanol. The solution was filtered through a $0.45 \mu$ membrane filter, diluted suitably and the absorbance of the resultant solution was measured by using UV-Visible spectrophotometer at $260 \mathrm{~nm}$ using $\mathrm{pH} 7.4$ phosphate buffers. $^{12}$

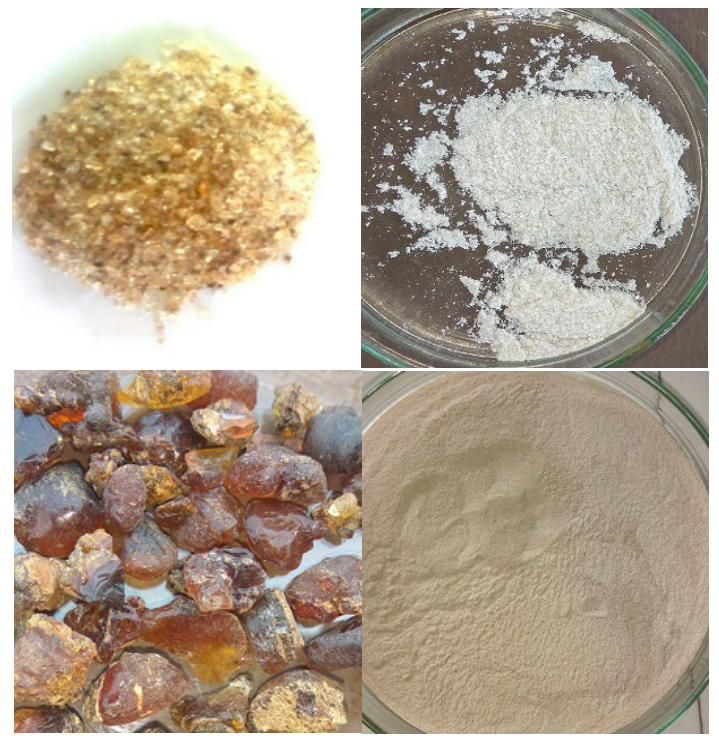

Figure 1: Cashew Gum, Dried Cashew Gum Powder. Neem Gum and Dried Neem Gum Powder.

\section{Table 1: Composition of Ketoprofen sustained released tablet.}

\begin{tabular}{|c|c|c|c|c|c|c|c|c|c|}
\hline S.No. & Ingredients & KNS1 & KNS2 & KNS3 & KNS4 & KCS5 & KCS6 & KCS7 & KCS8 \\
\hline 1 & Ketoprofen & 200 & 200 & 200 & 200 & 200 & 200 & 200 & 200 \\
\hline 2 & Neem Gum & 40 & 80 & 120 & 160 & - & - & - & - \\
\hline 3 & Cashew Gum & - & - & - & - & 40 & 80 & 120 & 160 \\
\hline 4 & MCC (Avicel pH 101) & 148 & 108 & 68 & 28 & 148 & 108 & 68 & 28 \\
\hline$' 5$ & Talc (1\%) & 4 & 4 & 4 & 4 & 4 & 4 & 4 & 4 \\
\hline 6 & Magnesium stearate (1\%) & 4 & 4 & 4 & 4 & 4 & 4 & 4 & 4 \\
\hline \multirow[t]{2}{*}{7} & PVP K30 (1\%) & 4 & 4 & 4 & 4 & 4 & 4 & 4 & 4 \\
\hline & Total weight(mg) & 400 & 400 & 400 & 400 & 400 & 400 & 400 & 400 \\
\hline
\end{tabular}

${ }^{\star}$ KNS- Ketoprofen Neem Gum Sustained released tablet, KCS- Ketoprofen Cashew Gum Sustained released tablet, PVP K30- Poly Vinyl Pyrrolidine K 30 grade 


\section{Release kinetics}

The analysis of drug release is an important mechanism but, complicated process and is practically evident in the case of matrix systems as a model dependent approach. The dissolution data were fitted into zero and first order for establishing drug release kinetics and Higuchi diffusion model. According to the Korsmeyer Peppas equation, the release exponent ' $n$ ' value is used to characterize different release mechanisms. For a dosage form in a cylindrical shape, if the $n$ value is 0.45 or less, the release mechanism follows Fickian diffusion. If ' $n$ ' value is $0.45<n>0.89$, the mechanism follows non-Fickian (anomalous) diffusion and when ' $n$ ' value is 0.89 it will be non-Fickian case II transport and if $n>0.89$ it will be non-Fickian super case II transport. ${ }^{16}$

\section{RESULTS}

\section{Drug Polymer Interaction/Compatibility study using FT-IR}

A physical mixture of drug and polymer was characterized by FT-IR spectral analysis for any physical as well as chemical alteration of drug characteristics. The spectra's of ketoprofen, ketoprofen- cashew mixture and ketoprofen -neem gum mixture were shown in Figure 2. From results, it was concluded that there was no interference in the functional group as the principle peaks of ketoprofen was found to be unaltered in the drug polymer physical mixture was shown in Table 2.

The Bulk density of various powder mixed blends prepared with different excipients was measured by a graduated cylinder. The bulk density was found in the range of $0.55-0.614 \mathrm{~g} / \mathrm{ml}$. The Tapped density of various powder mixed blends prepared with different excipients was measured by the graduated cylinder. The Tapped density was found in the range of $0.62-0.652 \mathrm{~g} / \mathrm{ml}$. Carr's index of various powder mixed blends, prepared with different excipients using bulk density and tapped density data, compressibility index was calculated. It was found in the range of 4.38- $11.29 \%$. The Hausner's ratio of various powder mixed blends, prepared with different excipients using bulk density and tapped density, Hausner's ratio was calculated. It was found in the range of 1.04- 1.14. The angle of repose ranged from $21.6-28.4^{\circ}$. The flow properties of powder blend in all formulations exhibit good flow and passable characteristics. The tablets were characterized concerning the angle of repose, bulk density, tapped density, Carr's index and drug content was shown in
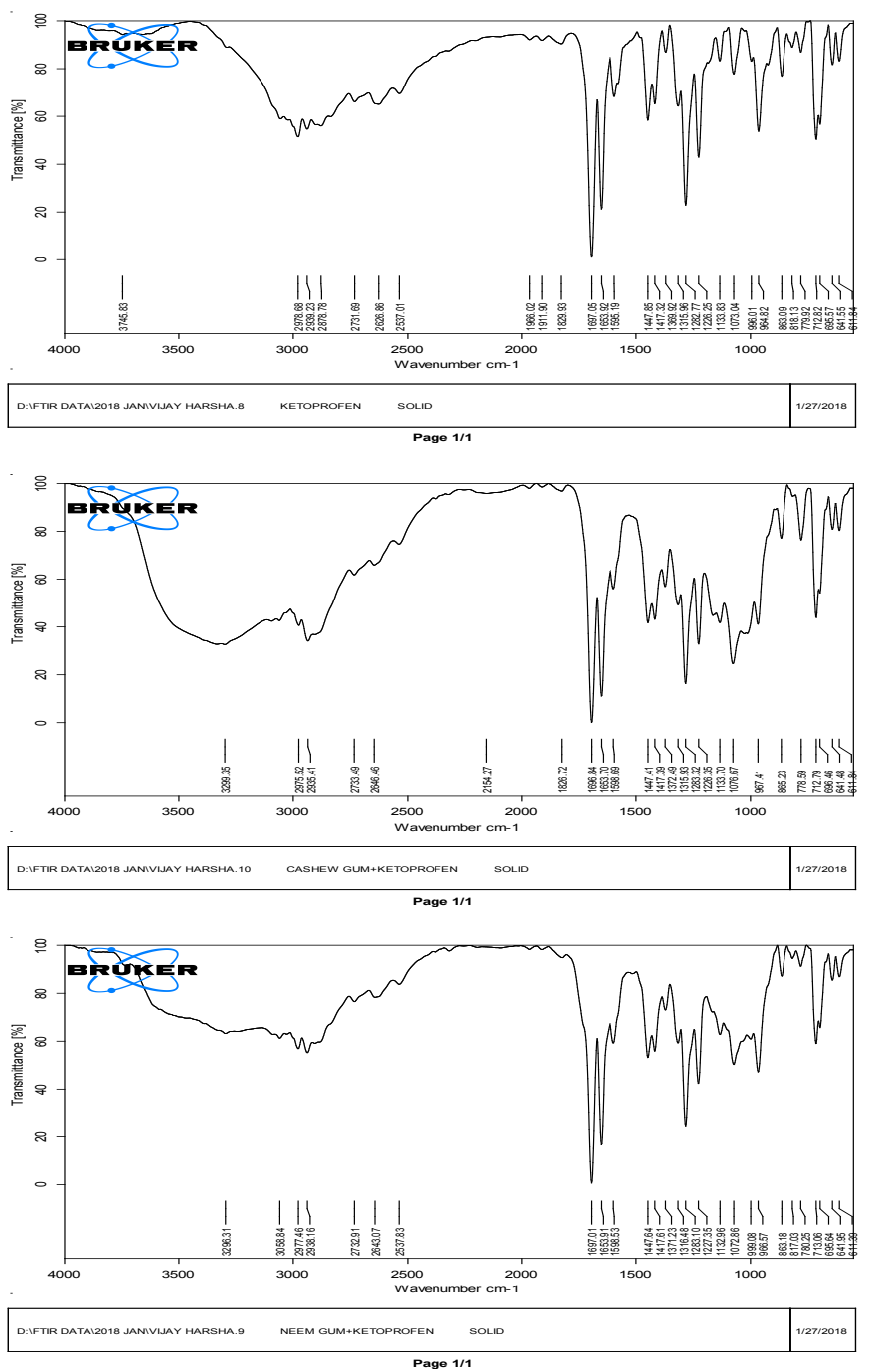

Figure 2: FT-IR Spectral Analysis of Ketoprofen, FT-IR spectral analysis of Physical mixture of Drug and neem gum and FT-IR spectral analysis of Physical mixture of Drug and cashew gum.

Table 2: FT-IR Spectral Analysis of Ketoprofen.

\begin{tabular}{ccc}
\hline Functional Groups of Ketoprofen & Characteristic Peak & Observed Peak \\
\hline C=O (Amide) & 1680 & 1675 \\
C=C & 1650 & 2978 \\
C-H Stretching & 3000 & 2254 \\
C-N Stretching & 2250 & Observed Peak \\
Functional Groups of Ketoprofen and Neem Gum & Characteristic Peak & 1697 \\
C=O (Amide) & 1680 & 1653 \\
C=C & 1650 & 2977 \\
C-H Stretching & 3000 & 695 \\
Phenyl Group & 690 & Observed Peak \\
Functional Groups of Ketoprofen and Cashew Gum & Characteristic Peak & 2978 \\
OH (Carboxyl Group) & 3000 & 1696 \\
C=O(Amide) & 1680 & 1283 \\
C-O Stretching & 1280 & 3299 \\
O-H Bending & 3300 & 712 \\
Phenyl Group & 690 and 750 & \\
\hline
\end{tabular}


Table 3. The angle of repose was less than $35^{\circ}$ and Carr's index values were less than 12 for the raw material of all the batches indicating good to fair flowability and compressibility. Hausner's ratio was less than 1.5 for all the batches indicating good flow properties.

The results of the uniformity of weight, hardness, thickness, friability and drug content of the tablets are given in Table 4 . All the tablets of different batches complied with the official requirements of uniformity of weight as their weights varied between $\pm 5 \mathrm{mg}$. The hardness of the tablets ranged from 5.5 to $6.8 \mathrm{Kg} / \mathrm{cm}^{2}$ and the friability values were less than $1 \%$ indicating that the matrix tablets were compact and hard. All the formulations satisfied the content of the drug as they contained 99.1 to $100.8 \%$ of ketoprofen and good uniformity in drug content was observed. Thus, all the physical attributes of the prepared tablets were found to be practice within control and shown in Table 4 . In vitro dissolution studies are performed sustained release tablets of Ketoprofen using different concentrations of the neem gum as a release retardant polymer in buffer $7.4 \mathrm{pH}$ for twelve hrs using USP dissolution apparatus type II. The dissolution rate was found to increase linearly with increasing concentration of polymer. The dissolution profiles of KNS1 to KNS4 formulations were shown in Figure 3. The formulations KNS1 released $99.97 \%$ of drug in $6 \mathrm{hrs}$, KNS2 released $99.5 \%$ of drug in 10 hrs, KNS3 released 99.2 of drug in 12 hrs and KNS4 released $90.13 \%$ of drug in 12 hrs Formulation KNS 3 con-

Table 3: Physical Properties of Pre-compression Blend

\begin{tabular}{cccccc}
\hline Formulation Code & The angle of repose $\left(^{\circ}\right)$ & Bulk Density $(\mathrm{g} / \mathrm{mL})$ & Tapped Density $(\mathrm{g} / \mathrm{mL})$ & Carr's Index (\%) & Hausner's ratio \\
\hline KNS1 & $22.5 \pm 0.44$ & $0.607 \pm 0.014$ & $0.647 \pm 0.042$ & $6.18 \pm 0.17$ & $1.06 \pm 0.001$ \\
KNS2 & $21.6 \pm 0.12$ & $0.566 \pm 0.016$ & $0.626 \pm 0.016$ & $9.58 \pm 0.24$ & $1.1 \pm 0.014$ \\
KNS3 & $28.4 \pm 0.24$ & $0.556 \pm 0.024$ & $0.612 \pm 0.025$ & $9.15 \pm 0.15$ & $1.14 \pm 0.024$ \\
KNS4 & $27.2 \pm 0.17$ & $0.55 \pm 0.029$ & $0.62 \pm 0.045$ & $11.29 \pm 0.45$ & $1.12 \pm 0.026$ \\
KCS5 & $24.96 \pm 0.48$ & $0.611 \pm 0.041$ & $0.639 \pm 0.043$ & $4.38 \pm 0.24$ & $1.04 \pm 0.018$ \\
KCS6 & $26.06 \pm 0.85$ & $0.614 \pm 0.015$ & $0.646 \pm 0.025$ & $4.95 \pm 0.41$ & $1.05 \pm 0.035$ \\
KCS7 & $25.03 \pm 0.25$ & $0.596 \pm 0.018$ & $0.652 \pm 0.057$ & $9.39 \pm 0.23$ & $1.09 \pm 0.021$ \\
KCS8 & $23.5 \pm 0.45$ & $0.599 \pm 0.016$ & $0.631 \pm 0.026$ & $5.34 \pm 0.17$ & $1.05 \pm 0.014$ \\
\hline
\end{tabular}

${ }^{*}$ Mean \pm S.D, $n=3$

Table 4: Physical Evaluation of Sustained release tablets.

\begin{tabular}{ccccc}
\hline $\begin{array}{c}\text { Formulation } \\
\text { code }\end{array}$ & $\begin{array}{c}\text { Average } \\
\text { weight } \\
\text { variation*(mg) }\end{array}$ & $\begin{array}{c}\text { Hardness* } \\
\left(\mathrm{Kg} / \mathrm{cm}^{2}\right)\end{array}$ & $\begin{array}{c}\text { Friability** } \\
(\%)\end{array}$ & $\begin{array}{c}\text { Drug } \\
\text { content* } \\
(\%)\end{array}$ \\
\hline KNS1 & $399 \pm 2.6$ & $5.5 \pm 0.110$ & $0.54 \pm 0.244$ & $99.1 \pm 0.18$ \\
KNS2 & $398 \pm 1.6$ & $5.9 \pm 0.112$ & $0.44 \pm 0.112$ & $98.2 \pm .0 .51$ \\
KNS3 & $399 \pm 1.8$ & $6.2 \pm 0.642$ & $0.26 \pm 0.198$ & $99.13 \pm 0.41$ \\
KNS4 & $397 \pm 1.3$ & $6.8 \pm 0.751$ & $0.21+ \pm 0.163$ & $97.9 \pm 0.14$ \\
KCS5 & $399 \pm 2.6$ & $6.7 \pm 0.612$ & $0.46 \pm 0.682$ & $99.25 \pm 0.41$ \\
KCS6 & $398 \pm 1.6$ & $5.5 \pm 0.115$ & $0.33 \pm 0.263$ & $99.15 \pm 0.52$ \\
KCS7 & $399 \pm 1.8$ & $5.8 \pm 0.130$ & $0.240 \pm 376$ & $100.8 \pm 0.24$ \\
KCS8 & $399 \pm 1.3$ & $6.7 \pm 0.786$ & $0.41 \pm 0.358$ & $98.2 \pm 0.55$ \\
\hline
\end{tabular}

"Mean \pm S.D, $n=3,{ }^{* *}$ Mean \pm S.D, $n=20$

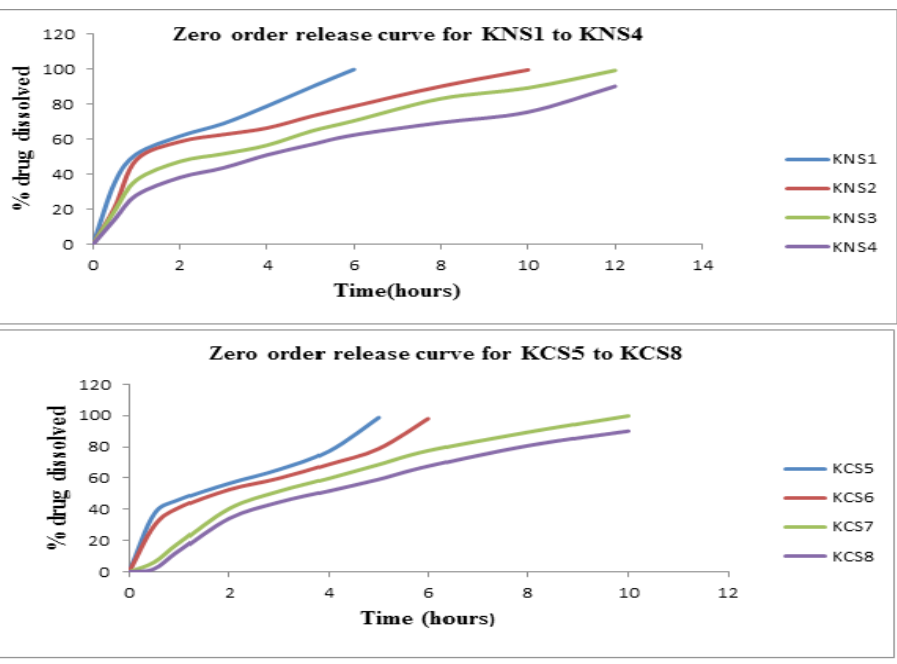

Figure 3: Zero order release rate profiles of formulations using neem gum and cashew gum.

Table 5: Kinetic analysis of formulations.

\begin{tabular}{ccccccc}
\hline Formulation Code & Zero order $\left(\mathrm{R}^{2}\right)$ & First order $\left(\mathrm{R}^{2}\right)$ & Higuchi plot $\left(\mathrm{R}^{2}\right)$ & Pappas plot $\left(\mathrm{R}^{2}\right)$ & $n$ & Hixson Crowell $\left(\mathrm{R}^{2}\right)$ \\
\hline KNS1 & 0.931 & 0.849 & 0.991 & 0.991 & 0.387 & 0.907 \\
KNS2 & 0.903 & 0.901 & 0.979 & 0.949 & 0.438 & 0.936 \\
KNS3 & 0.943 & 0.912 & 0.994 & 0.984 & 0.468 & 0.954 \\
KNS4 & 0.951 & 0.972 & 0.996 & 0.987 & 0.523 & 0.964 \\
KCS5 & 0.944 & 0.857 & 0.985 & 0.975 & 0.393 & 0.867 \\
KCS6 & 0.957 & 0.868 & 0.989 & 0.98 & 0.444 & 0.883 \\
KCS7 & 0.965 & 0.88 & 0.989 & 0.972 & 0.89 & 0.959 \\
KCS8 & 0.967 & 0.911 & 0.988 & 0.938 & 1.11 & 0.968 \\
\hline
\end{tabular}


taining $120 \mathrm{mg}$ of neem gum have recorded percentage of drug release was 98.2 respectively in $12 \mathrm{hrs}$ and selected as optimized formulation for sustained release. The dissolution rate was found to increase linearly with increasing concentration of polymer. The dissolution profiles of KCS5 to KCS8 formulations were shown in Figure 3. The formulations KCS5 released $98.78 \%$ of the drug is 5 hrs, KCS6 released $98.05 \%$ of the drug is 6 hrs, KCS7 released 99.8 of drug in 10 hrs and KCS8 released 99.4\% of the drug in $12 \mathrm{hrs}$. Formulation KCS8 containing $160 \mathrm{mg}$ have recorded percentage of drug release was $99.4 \%$ respectively in $12 \mathrm{hrs}$ and selected as the optimized formulation of for sustained release.

\section{Kinetic analysis of dissolution data}

To analyze the drug release mechanism the in vitro release data was fitted into various release equations and kinetic models zero order, first order, Higuchi and Korsmeyer Peppas model. The release kinetics of Optimized formulation is shown in Table 5.

\section{DISCUSSION}

In vitro drug release data of all the sustained formulations was subjected to the goodness of fit test by linear regression analysis according to zero order and first order kinetic equations, Higuchi's and Korsmeyer Peppas models to ascertain the mechanism of drug release. The release kinetics was evaluated by fitting the drug release data to five kinetic models. The kinetic model with the highest correlation coefficient value $\left(r^{2}\right)$ was selected as the model that best described the dissolution data. The results of correlation coefficients $\left(r^{2}\right)$ are summarized in Table 5 and plots are shown in Figure 3. From Higuchi and Peppas data, it was evident that the drug is released by fickian diffusion mechanism $(0.5<n)$. From the kinetic data of factorial formulations in Table 5. This data reveals that drug release follows fickian diffusion case-II transport mechanism Peppas model. From the above data, it can be seen that the optimized formulation of KCS8 shows zero order release kinetics (' $r{ }^{2}$ ' values in the range of 0.967). From Higuchi and Peppas data, it was evident that the drug is released by non-Fickian diffusion mechanism $(0.5<n<0.89)$. From the kinetic data of factorial formulations in Table 5, it is evident that KCS8 formulation has shown drug release by zero order kinetics. This data reveals that drug release follows non-Fickian diffusion super case -II transport mechanism Peppas model.

\section{CONCLUSION}

Once daily sustained release tablet of ketoprofen has achieved the objective of controlled drug delivery with prolonged drug release, cost effective, low dose and frequency of administration and hence improved patient compliance. Thus, it may be concluded that the once daily tablet of ketoprofen sustained release tablet can be the best alternative to conventional dosage forms with more frequency of administration. The sustained release tablet can be administered to patients. The present study was undertaken to design oral sustained release tablet of ketoprofen. Results indicated that the release of the drug from the ketoprofen tablets using cashew gum and neem gum as polymers for sustained release layer showed desired drug release. So, Sustained release tablets could be a potential dosage form for delivering ketoprofen. The success of the in vitro drug release studies recommends the product for further in vivo studies. Formula KCS8 using cashew gum at 40\% concentration level released 99.4\% drug in $12 \mathrm{hrs}$ is selected as optimized formula, it is evident that
KCS8 formulation has shown drug release by zero order kinetics. This data reveals that drug release follows erosion, fickian diffusion super case -II transport mechanism Peppas model.

\section{ACKNOWLEDGEMENT}

We, authors wish to thank all those who helped us to do this research work. Thankful to Principal, St. Ann's College of Pharmacy, Vizianagaram, Department of Pharmaceutical Technology, University College of Pharmaceutical Sciences, Andhra University, Visakhapatnam, India for providing necessary facilities.

\section{CONFLICT OF INTEREST}

The authors declare no conflict of interest.

\section{ABBREVIATIONS}

FT-IR: Fourier Transformer Infrared Spectrometer; NSAID: NonSteroidal Anti-Inflammatory Drug; CCG: Crude Cashew Gum; CNG: Crude Neem Gum; PVP: Polyvinyl Pyrrolidine.

\section{REFERENCES}

1. Tilak RB, Meenakshi K, Roshan L, Anubha G. Natural Gums and Modified Natural Gums as Sustained-Release Carriers. Drug Dev Ind Pharm. 2000;26(10):102538.

2. Zatz JL, Kushla GP. Oral aqueous suspensions and gels in Pharmaceutical Dosage Forms: Disperse Systems. Marcel Dekker, New York, NY, USA. 1989.

3. Jani GK, Shah DP, Prajapatia VD, Jain VC. Gums and mucilages: Versatile excipients for pharmaceutical formulations. Asian J Pharm. 2009;4(5):309-23.

4. Whistler RL. Drug-release retarding polymers are the key performers in Industrial Gums, Academic Press, London, UK, $2^{\text {nd }}$ edition. 1996.

5. Kulkarni GT, Gowthamarajan K, Dhobe RR, Yohanan F, Suresh B. Development of controlled release spheroids using natural polysaccharide as release modifier. Drug Deliv. 2005;12(4):201-6.

6. Lima RDN, Lima JR, DeSalis CR, Moreira RA. Cashew-tree (Anacardium occidentale L.) exudate gum: A novel bioligand tool. Biotechnol Appl Biochem. 2002;35(1):45-53.

7. Gangurde AB, Malode SS, Bhambar RS. Preliminary evaluation of neem gum as tablet binder. Indian $\mathrm{J}$ of Pharmaceutical Education and Research. 2008:42(4):344-7.

8. Abdul AH, Suresh KC, Kumar BA. Permeation studies of diclofenac sodium from Ficus carica fruit mucilage matrices for transdermal delivery. Int Journal Chem Tech Res. 2010;2(2):937-41.

9. Ganesh GNK, Sureshkumar R, Jawahar N, Senthil V, Venkatesh DN, Srinivas MS. Preparation and evaluation of sustained release matrix tablet of diclofenac sodium using natural polymer. J Pharm Sci Res. 2010;2(6):360-8.

10. Joshi Y, Chaudhary RK, Teotia UVS. Formulation and evaluation of diclofenac sodium sustained release matrix tablets using Aegle marmelos gum. Int J Curr Trends Pharm Res. 2013;1(3):174-80

11. Sharada B, Basavaraj BV, Bharath S, Deveswaran R, Madhavan V. Sustained release matrix tablets of indomethacin using Hibiscus rosa-sinensis as release retardant. Schol Res Libr. 2012;4(1):227-33.

12. Khan J, Yuen KH, Bee HN, Chitneni M, Osmaneg SA, Al-Dhali S, et al. Preparation and in vitro evaluation of different controlled release polymeric matrices containing ketoprofen. Health Med. 2010;4(2):386-92.

13. Shohin IE, Kulinich JI, Ramenskaya GV, Vasilenko GF. Evaluation of in vitro equivalence for drugs containing BCS class II compound ketoprofen. Dissolution Technol. 2011;19(1):26-9.

14. Abayomi TO, Gbenga A. Neem Gum as a Binder in a Formulated Paracetamo Tablet with Reference to Acacia Gum BP. AAPS Pharm SciTech. 2014;15(2):50010.

15. Chowdary KPR, Rao KSP. Formulation Development of Pioglitazone Tablets Employing $\beta$ Cyclodextrin-Poloxamer 407-PVP K30: A Factorial Study. Der Pharmacia Lettre. 2011;3(6):24-30.

16. Singh I, Kumar P. Pre formulation studies for direct compression suitability of cefuroxime axetil and paracetamol: A graphical representation using sedem diagram. Acta Pol Pharm. 2012;69(1):87-93.

Cite this article: Baratam SR, Made VH. Preparation and Characterisation of Sustained Released Dosage form for Ketoprofen using Natural Gums. Int. J. Pharm. Investigation. 2020;10(1):54-8. 